\section{Prednisolone as an appetite stimulant in patients with cancer}

Anorexia is a common complaint of patients with cancer at all stages of their disease, ${ }^{2}$ and a random survey of 110 patients attending the department of clinical oncology at Gartnavel General Hospital showed it to be present in $43 \%$ of cases. Although no controlled trials have been performed, ${ }^{3}$ steroids have been used empirically for many years to promote wellbeing and stimulate appetite in patients with cancer. The aim of this study was to examine the effectiveness of prednisolone compared with placebo in stimulating appetite and increasing body weight, energy intake, and general wellbeing in a group of patients with cancer.

\section{Patients, methods, and results}

We studied 61 patients complaining of poor appetite or weight loss and with no contraindication to steroids. The study was conducted as a double blind crossover trial, fixed dosages being used to simplify treatment. Patients were given prednisolone, $5 \mathrm{mg}$ thrice daily for two weeks and then for a third week when the dosage was reduced; and placebo, one tablet thrice daily for two weeks and then for a further week when the dosage was reduced. The order of treatment was randomised.

Assessment was carried out after two and five weeks of treatment, at the same time of day on each occasion. These timings coincided with patients' outpatient appointments. At each visit weight was recorded and a 24 hour dietary recall history was noted, which was analysed by computer using a program devised by Tayside health centre that gave the protein, carbohydrate, fat, and energy contents of the diet. Each patient completed a questionnaire and visual analogue scales assessing appetite, nausea, vomiting, mood, and wellbeing and reported any side effects of treatment.

Forty one of the 61 patients could be evaluated ( 16 men and 25 women, age range $27-80$ (mean 60 ) years). They had various solid tumours, gastrointestinal tumours being most common. All types of tumour showed a similar pattern of response to treatment. Twenty three patients were not receiving any chemotherapy during the study; 18 patients received a variety of different combination chemotherapies, which were timed to coincide with the study. None of the patients had had recent surgery and none had hypercalcaemia.

Of the 20 patients who were excluded from the study, nine were randomised to take prednisolone first and 11 placebo first. Six patients died and three were admitted to hospital during the study; four patients started chemotherapy during the study and so could not be evaluated. Seven patients stopped taking their tablets during the study and were excluded. In most of these patients appetite continued to deteriorate or remained at pretreatment levels. No side effects were reported by any of the patients.

Response rates in the groups receiving and not receiving chemotherapy reflected the results obtained in the entire group of patients. The $\chi^{2}$ test was applied to the proportions of patients who responded. The table shows the results.

Results in 41 patients (figures are numbers (\%) of patients)

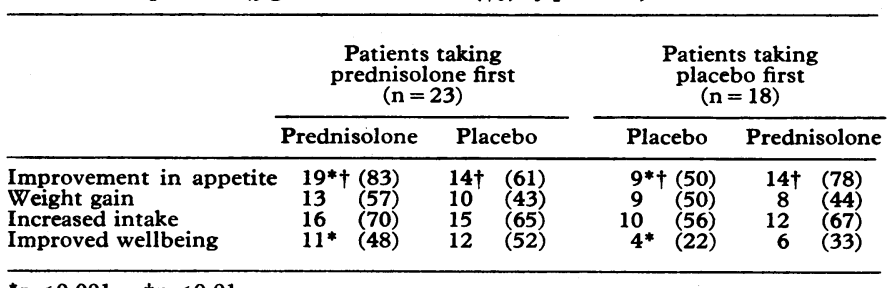

${ }^{*} \mathrm{p}<0.001 . \quad+\mathrm{p}<0.01$.

\section{Comment}

Prednisolone was significantly better than placebo $(p<0.001)$ in improving appetite in patients with cancer in the short term; this improvement was seen also when patients who had been taking placebo crossed over to receive prednisolone $(p<0.01)$. There was a major placebo effect $(50 \%)$, confirming a psychological basis for anorexia in some of the patients. ${ }^{45}$

Weight did not change in either group of patients, indicating that no appreciable water retention occurred with this dose of prednisolone. When taking prednisolone the patients showed a trend towards increased intake and a significant increase in wellbeing $(p<0.001)$.

In future studies we shall examine the effectiveness of prednisolone taken for longer periods in maintaining the initial response of some patients, for whom the benefits of an improved nutritional state may outweigh the drawbacks of long term steroids.
We thank Roussel Laboratories for their help in providing prednisolone and placebo tablets. Thanks are also due to the Cancer Research Campaign for funding this project and to Carolyn Barbour, dietician at Heathfield Hospital, for assisting in the study.

${ }^{1}$ DeWys W. Anorexia as a general effect of cancer. Cancer 1979;43:2013-9.

2 Woodbine G. The care of patients dying from cancer. $\mathcal{f} R$ Coll Gen Pract $1982 ; 32: 685-9$.

${ }^{3}$ Oliver GJ. The care of patients dying from cancer. $\mathcal{F}$ R Coll Gen Pract 1983;33:123.

${ }^{4}$ Holland TCB, Rowland T, Plumb M. Psychological aspects of anorexia in cancer patients. Cancer Res $1977 ; 37: 2425-8$.

${ }^{5}$ Bernstein IL. Physiological and psychological mechanisms of cancer anorexia. Cancer Res 1972;42 (suppl):715-20.

(Accepted 26 August 1983)

Gartnavel General Hospital, Glasgow G12 9LX

JOANNE C WILLOX, MB, CHB, cancer research campaign fellow

JEAN CORR, DIP DIET, SRD, senior dietician

JANE SHAW, BSC, MPS, staff pharmacist

MARGARET RICHARDSON, BSC, MPS, principal pharmacist

KENNETH C CALMAN, MD, professor of clinical oncology

Department of Dietetics, Heathfield Hospital, Ayr

MARY DRENNAN, BSC, SRD, senior dietician

Correspondence and requests for reprints to: $\mathrm{Dr} \mathrm{J} \mathrm{C}$ Willox.

\section{Clinical remission of membranous glomerulonephritis in primary biliary cirrhosis with cutaneous vasculitis}

Primary biliary cirrhosis is a disease of unknown aetiology, and extrahepatic manifestations are common. ${ }^{1}$ Two cases in which primary biliary cirrhosis and glomerulonephritis seemed to occur simultaneously have been described ${ }^{3}{ }^{4}$; one of these patients had cutaneous vasculitis. We describe a case in which the nephrotic syndrome preceded by 10 years the diagnosis of primary biliary cirrhosis, which was followed after five years by the development of cutaneous lesions.

\section{Case report}

A 66 year old woman was admitted to hospital in 1981 for a small peptic ulcer. She had a long medical history. In 1963 a cholecystectomy had been performed because of cholecystitis. The liver surface was described as normal. In 1965 she had been treated for pneumococcal meningitis; the alkaline phosphatase activity was not recorded. Later that year the nephrotic syndrome had been diagnosed, with "large protein losses." Renal function was normal, and the urinary sediment showed occasional granular casts. From 1965 to 1974 her protein losses decreased.

In 1975 activities of alkaline phosphatase, serum aspartate transaminase, and serum alanine transaminase were raised, and a few months later she developed pruritus. A liver biopsy specimen showed not very active chronic hepatitis. Cholestyramine was prescribed. Because proteinuria persisted $(<3 \mathrm{~g} / 24 \mathrm{~h})$ a kidney biopsy specimen was also obtained; the few glomeruli present showed considerable thickening of the capillary basement membrane of the glomerular loops with formation of multiple spikes on the epithelial surface and small cavities within the membrane. Immunofluorescence of frozen tissue showed granular deposits along the basement membrane of IgG, IgM, Clq, and C3c, which confirmed the diagnosis of membranous glomerulopathy. In 1977 antibodies to mitochondria were strongly positive and $\mathrm{IgM}$ concentration was raised ( $370 \mathrm{IU} / \mathrm{ml}$ (normal 40-225 IU $/ \mathrm{ml}$ ).

On admission in 1981 she mentioned having had crops of itching pikn spots for the past three years that were different from the continual itch that had been bothering her for years. On examination she was a slender woman in good general health and with normal blood pressure; she did not have jaundice. The skin was diffusely pigmented, without scratch marks. The liver margin was felt $4 \mathrm{~cm}$ below the ribs; the spleen was not enlarged. Urine protein was absent and the sediment normal. Erythrocyte sedimentation rate was $47 \mathrm{~mm}$ in the first hour; creatinine concentration $86 \mu \mathrm{mol} / 1(973 \mu \mathrm{g} /$ $100 \mathrm{ml}$ ); total bilirubin concentration $16 \mathrm{mmol} / 1(936 \mathrm{mg} / 100 \mathrm{ml})$; alkaline phosphatase activity $28.7 \mathrm{U}$ (normal $3 \cdot 0-7 \cdot 8 \mathrm{U}$ ); serum aspartate transaminase $89 \mathrm{U}$ (normal $<40 \mathrm{U}$ ); serum alanine transaminase $86 \mathrm{U}$ (normal $<30 \mathrm{U}$ ); total protein $87 \mathrm{~g} / 1$; albumin $35.6 \mathrm{~g} / 1$; gammaglobulin $13.2 \mathrm{~g} / 1$; IgG $11.7 \mathrm{~g} / 1$ (normal 8-18 $\mathrm{g} / \mathrm{l}$ ); IgA $6.0 \mathrm{~g} / 1$ (normal $0.9-4.5 \mathrm{~g} / 1$ ); and IgM 4.1 $\mathrm{g} / \mathrm{l}$ (normal $0 \cdot 7-2 \cdot 8 \mathrm{~g} / \mathrm{l}$ ). Liver biopsy was repeated and definitely confirmed the diagnosis of primary biliary cirrhosis. 
While she was in hospital the "itching spots" developed: these were pink, slightly raised papules of $1.5-2.5 \mathrm{~mm}$ in diameter scattered over the whole body. Skin biopsy specimens were immediately taken from a new lesion and from nearby normal skin. Immunofluorescence staining showed the presence of tiny deposits of IgM and complement around small vessels in the upper dermis and slight mononuclear perivascular infiltrate. In the normal skin the reaction was far less pronounced. Traces of IgM were present perivascularly, but there was little complement. These changes were considered to be compatible with the deposition of circulating IgM immune complexes and activation of complement causing vasculitis.

\section{Comment}

As IgM is normally absent in the deposits of membranous glomerulonephritis the presence of IgM in the glomeruli of our patient (and the patient of Rai $e t a^{3}$ ) is remarkable. Our patient also shows that, though IgM is present in the normal skin of patients with primary biliary cirrhosis, ${ }^{5}$ cutaneous lesions and vasculitis occur only in the presence of immune complexes containing IgM and complement. In patients with primary biliary cirrhosis a high proportion of immune complexes contain IgM; most are complement fixing. ${ }^{2}$ We believe that this report strengthens the case for IgM glomerulonephritis and cutaneous vasculitis being extrahepatic manifestations of primary biliary cirrhosis, which may well be mediated by the deposition of complement binding IgM immune complexes.

1 Golding PL, Smith M, Williams R. Multisystem involvement in chronic liver disease. Am $\mathcal{F}$ Med 1973;55:772-82.

2 Wands JR, Dienstag JL, Bahn AK, Feller ER, Isselbacher KJ. Circulating immune complexes and complement activation in primary biliary cirrhosis. N Engl f Med 1978;298:233-7.

${ }^{3}$ Rai GS, Hamlyn AN, Dahl MGC, Morley AR, Wilkinson R. Primary biliary cirrhosis, cutaneous capillaritis, and IgM-associated membranous glomerulonephritis. Br Med f 1977;i :817.

- Morris JA, McIllmurray MB. Primary biliary cirrhosis and focal glomerulonephritis. Br Med F 1981 ;282:1836-7.

5 Lindgren S, Eriksson S, Löfberg H, McKay J. IgM deposition in skin biopsies from patients with primary biliary cirrhosis. Acta Med Scand $1981 ; 210: 317-20$.

(Accepted 26 April 1983)

Department of Internal Medicine, Bergwegziekenhuis, Rotterdam, The Netherlands

D J REITSMA, MD, specialist in internal medicine

Stichting Pathologische Anatomie, Rotterdam, Noord S GRATAMA, MD, pathologist

Department of Pathology, Slotervaartriekenhuis, Amsterdam THEA M VROOM, MD, head of department

\section{Somatostatin in paroxysmal supraventricular and junctional tachycardia}

Somatostatin acts as a negative inotropic agent in isolated spontaneously beating auricles of guinea pigs. It produces this effect by direct action on atrial myocardial cells, possibly by reducing the influx of calcium ions into these cells. ${ }^{1}$ It has been shown that the cholinergic postganglionic neurons of the cardiac vagus contain material similar to somatostatin that appears to be tetradecapeptide somatostatin. ${ }^{2}$ We observed a decrease in heart rate in a group of patients with psoriasis treated with somatostatin. ${ }^{3}$ These experimental and clinical observations led us to give intravenous somatostatin to six patients with paroxysmal supraventricular and junctional tachycardia to see whether it would restore sinus rhythm.

\section{Patients, methods, and results}

We studied four women and two men with recurrent attacks of electrocardiographically documented paroxysmal supraventricular or junctional tachycardia who had been admitted to hospital. They comprised a 62 year old woman (case 1) with paroxysmal supraventricular tachycardia; two women aged 38 and 40 (cases 2 and 3), with paroxysmal supraventricular tachycardia in the Wolff-Parkinson-White syndrome; a 71 year old man (case 4) with paroxysmal supraventricular tachycardia in the sick sinus syndrome and with a permanent cardiac pacemaker; and a man and a woman aged 34 and 27 respectively (cases 5 and 6 ) with paroxysmal junctional tachycardia.

We observed the patients 30 minutes to 24 hours after the onset of paroxysmal tachycardia. Administration of cyclic somatostatin (Serono, Italy) was started 10-15 minutes after ineffective vagal manoeuvres. Altogether $25 \mu \mathrm{g}$ somatostatin in $0.154 \mathrm{~mol}$ saline ( $1 / 10$ volume/volume dilution) was injected as a bolus every two minutes while continuous electrocardiography was performed. Voluntary informed consent was obtained from each patient.

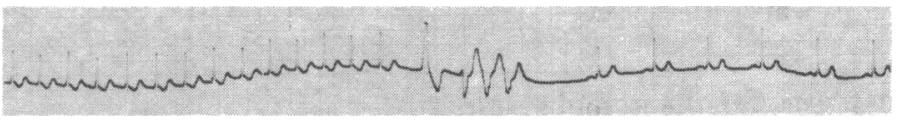

Electrocardiogram in lead II showing transition from paroxysmal supraventricular tachycardia to sinus rhythm in case 3 . Paper speed $25 \mathrm{~mm} / \mathrm{s}$.

Sinus rhythm was restored in five of the six patients, after administration of $175-200 \mu \mathrm{g}$ somatostatin-that is, about 15 minutes after the start of treatment. The figure shows the transition from paroxysmal supraventricular tachycardia to sinus rhythm in case 3. Despite the administration of $500 \mu \mathrm{s}$ somatostatin intravenously sinus rhythm was not achieved in the remaining patient, who had paroxysmal junctional tachycardia; a decreased ventricular rate with variable but transient atrioventricular dissociation was observed, however, soon after the treatment.

\section{Comment}

This report shows that intravenous administration of somatostatin may interrupt paroxysmal supraventricular tachycardia in man. Somatostatin is a potent inhibitor of several hormonal secretions. This effect has been related to an impaired uptake of calcium ions, which may be the common mechanism for the blocking action of somatostatin in different secretory cells. ${ }^{4}$ In addition, in isolated $\beta$ cells somatostatin reduces the accumulation of intracellular calcium by its primary activation of cell membrane permeability to potassium ions. ${ }^{5}$ In guinea pigs somatostatin produces a negative inotropic action associated with a calcium antagonist effect, probably dependent on binding to specific atrial receptors. ${ }^{2}$

The effect of somatostatin on supraventricular tachycardia is probably caused by an action on the atrioventricular node, related most probably to a calcium antagonist effect. Somatostatin has no effect on sodium or potassium adenosine triphosphatase $e^{5}$ and does not have a beta blocking action. 1

In Bufo marinus toads stimulation of the vagus nerve evokes release of somatostatin with a consequent decrease in the heart rate and force of atrial contraction. ${ }^{2}$ Possibly in man too somatostatin is present in vagal fibres and may play a physiological part in the autonomic control of cardiac action. Its minimal untoward effects and absence of toxicity make it a possible agent for treating arrhythmias.

1 Quirion R, Regoli D, Rioux F, St-Pierre S. An analysis of the negative inotropic action of somatostatin. Br F Pharmacol 1979;66:251-7.

2 Campbell G, Gibbins IL, Morris JB, et al. Somatostatin is contained in and released from cholinergic nerves in the heart of the toad Bufo marinus. Neuroscience 1982;7:2013-23.

3 Ghirlanda G, Uccioli L, Perri F, et al. Epidermal growth factor, somatostatin and psoriasis. Lancet $1983 ; \mathrm{i}: 65$.

4 Bhathena SJ, Perrino PV, Voyles NR, et al. Reversal of somatostatin inhibition of insulin and glucagon secretion. Diabetes 1976;25:1031-40.

- Pace CS, Tarvin JT. Somatostatin: mechanism of action in pancreatic islet $\beta$-cells. Diabetes $1981 ; 30: 836-42$.

(Accepted.14 September 1983)

Istituto di Patologia Medica, Universita Cattolica del Sacro Cuore, 00168 Rome, Italy

A V GRECO, MD, professor

GIOVANNI GHIRLANDA, MD, assistant

CARLO BARONE, $\mathrm{MD}$, assistant

ALDO BERTOLI, MD, assistant

SALVATORE CAPUTO, $M D$, assistant

LUIGI UCCIOLI, MD, assistant

RAFFAELE MANNA, MD, assistant

Correspondence to: Professor A V Greco. 